\title{
Principais sintomas e alterações imunológicas decorrentes da infecção pelo vírus HIV: uma revisão bibliográfica
}

\author{
Main symptoms and immunological changes resulting from HIV infection: a bibliographic \\ review
}

Principales sintomas y alteraciones inmunológicas decorrientes de la infección de virus HIV: una revisión bibliográfica

Jhony Oliveira Dias ${ }^{1}$, Sandy Gabryelle Carvalho de Sousa, Denis Rômulo Leite Furtado², Alex Vandro Silva de Oliveira ${ }^{3}$, Germano Soares Martins ${ }^{4}$.

\section{RESUMO}

Objetivo: Realizar um levantamento bibliográfico dos sintomas e alterações imunológicas decorrentes da infecção do Vírus da Imunodeficiência Humana (HIV). Métodos: Revisão Integrativa da Literatura, no período de agosto e setembro de 2019. Procurando responder à pergunta norteadora: quais os principais sintomas e alterações imunológicas decorrentes da infecção do vírus da imunodeficiência humana - HIV em seus portadores entre 2010 e 2019? Sendo selecionados dez estudos. Resultados: O portador do vírus HIV, deve apresentar em seu organismo um número maior de células T CD4+, isso se o paciente não fizer uso dos antirretrovirais. Os estudos mostraram que os pacientes com HIV, vivem um tempo sem serem cientes da doença, o portador é conhecedor da infecção após a realização de testes específicos, ou através da infecção de qualquer doença oportuna que irá lhe causar grandes prejuízos. Considerações finais: O levantamento dos estudos evidenciou que o HIV estar presente em todas as populações desde jovens aos idosos, e sua maneira silenciosa de viver no organismo, pode proporcionar um diagnóstico tardio. A infecção pelo HIV não apresenta sintomas evidentes, eles são vistos a partir das co-infecções de doenças oportunas.

Palavras-chave: Doenças do sistema imunitário, Infecções por HIV, Sinais e sintomas, HIV.

\begin{abstract}
Objective: Conduct a literature review of the symptoms and immunological changes caused by Human Immunodeficiency Virus Infection (HIV). Methods: Integrative Literature Review, from august and september 2019. Looking to answer the guiding question: what are the main symptoms and immunological changes resulting from the infection of the human immunodeficiency virus - HIV in their carriers between 2010 and 2019? Being selected ten studies. Results: The carrier of the HIV should have a larger number of CD4 + T cells in his body if the patient is not using antiretrovirals. Studies have shown that patients with HIV, live for a while without being aware of the disease, the carrier is aware of the infection after performing specific tests, or through the infection of any timely disease that will cause him great harm. Final Remarks: The survey showed that HIV is present in all populations since young to elderly, and its silent way of living in the body, can provide a late diagnosis. HIV's infection has no obvious symptoms they are seen from the co-infections of timely diseases.
\end{abstract}

Keywords: Immune system diseases, HIV Infection, Signs and symptoms, HIV.

\footnotetext{
1 Ensino Superior do Piauí (AESPI), Teresina-PI. *E-mail: Jhony-dias1298@hotmail.com

2 Universidade Estadual do Maranhão (UFMA), São Luís-MA.

${ }^{3}$ Centro Universitário UNINOVAFAPI, Teresina-PI.

${ }^{4}$ Centro Universitário UNINASSAU, Teresina-PI.
} 


\section{RESUMEN}

Objectivo: realizar un levantamiento bibliográfico de los sintomas y alteraciones inmunológicas decorrientes de la Infección de la Imunodeficiencia Humana (HIV). Metodos: Revisión integrativa de la Literatura, no periodo de agosto y septiembre de 2019. Buscando responder la pregunta norteadora: ¿Cuales los principales sintomas de la imunodeficiencia humana - HIV en sus portadores entre 2010 y 2019? Después de tener seleccionados diez estudios. Resultados: El portador de lo virus HIV, debe presentar en su organismo un número mayor celular T CD4+, eso si el paciente no hizo uso de los antirretrovirales. Los estudios mostraron que los pacientes con HIV, viven un tiempo sin ser conscientes de su condición, el portador es conocedor de la infección después de la realización de testes especificos, o por medio de la infección de cualquiera enfermedad oportuna que irá causarles grandes prejuicios. Consideraciones finales: El levantamiento de los estudios logrou que el HIV esta presente en todas las poblaciones desde jóvenes hasta idosos, y su manera silenciosa de vivir en lo organismo, puede proporcionar un diagnóstico tardio. La infección por el HIV no presenta sintomas evidentes, ellos son mirados a partir de sus co-infecciones de enfermedades oportunas.

Palabras clave: Enfermedades del sistema inmunitario, Infecciones por HIV, Sinales y sintomas, HIV.

\section{INTRODUÇÃO}

A síndrome da imunodeficiência adquirida (AIDS) é causada pelo Vírus da Imunodeficiência Humana (HIV) que provoca uma supressão do sistema imune e torna o indivíduo susceptível a infecções oportunas que não tratadas levam o indivíduo ao óbito (MELO BP, et al., 2017).

Rachid M e Schechter A (2017) diz que a infecção pelo HIV é dívida em três fases, sendo elas a fase aguda, também conhecida como síndrome de soro conversão, a fase assintomática e a fase sintomática. Sem interversões terapêuticas a mediana de progressão da fase aguda até a fase sintomática é de aproximadamente 10 anos, podendo variar entre seus portadores. O tratamento atual é o uso da terapia antirretroviral (TARV) sendo uma estratégia farmacológica com proposito de restaurar o sistema imunológico e melhora na qualidade de vida em pessoas vivendo com HIV/aids (MELO BP, et al., 2017). A fase aguda tem um quadro clinico que varia desde síndrome gripal até mononucleose-símile, febre, astenia, faringite, mialgia, artralgia, cefaleia, dor retrorbicular e linfadenopatia. Adenomegalias podem ser mais evidentes na segunda semana, envolvendo gânglios axilares, occipitais e cervicais.

$\mathrm{Na}$ fase assintomática os indivíduos infectados pelo HIV que nunca apresentaram manifestações clinicas associadas à imunodeficiência causada pela infecção, onde as avaliações laboratoriais iniciais devem fazer parte do hemograma, obtendo a contagem de linfócitos Cluster of differentiation (CD4+). Já a fase sintomática pode ser dívida em precoce e tardia, a precoce caracteriza-se pela ocorrência de manifestações que aparecem mais comuns naqueles com imunodeficiência inicial, porem podem ocorrer em indivíduos imunocompetentes, e na fase tardia ocorre de infecções e/ou neoplasias que raramente afetam indivíduos imunocompetentes (RACHID A e SCHECHTER A, 2017).

Desde 1996 começou um avanço das pesquisas clínicas e farmacológicas surgindo a terapia antirretroviral altamente potente, um regime de tratamento para diminuir a replicação viral e o progresso da infecção pelo HIV, podendo ser combinado três ou mais antirretrovirais que atuam nas diferentes etapas da replicação viral. Esse tratamento trouxe significativas melhoras na qualidade e na expectativa de vida das pessoas vivendo com HIV/aids (FERNANDES NM, et al., 2017).

Segundo Lago RF e Costa NR (2017), entre os países em desenvolvimento o Brasil foi o primeiro a disponibilizar gratuitamente pela rede pública de saúde medicamentos antirretrovirais. Sendo considerado uma resposta de grande relevância frente a epidemia de aids envolvendo as três grandes esferas de atenção à saúde prevenção, tratamento e respeito aos direitos humanos, além de importante conscientização da população civil, considerado como fator intrínseco para efetivação deste importante ganho.

A terapia para HIV tem grande significado para a melhora da condição e saúde dos portadores do vírus, atualmente o uso dessa medicação pode reduzir em até $96 \%$ as chances de transmitir o vírus. Neste sentido os antirretrovirais têm efeitos expressivos na prevenção do HIV, o que contribui efetivamente no equilíbrio 
epidemiológico e aponta um aumento progressivo pela busca desses medicamentos (LAGO RF e COSTA NR, 2017).

O Departamento de Informática do Sistema Único de Saúde (DATASUS) que tem como responsabilidade prover os órgãos do SUS de sistemas de informação e suporte de informática, necessários ao processo de planejamento, operação e controle no seu último consolidado em 2017 de casos diagnosticados no Brasil um número de 15.653 casos, na região nordeste de 2.040 casos, apresentando um maior número de casos no estado da Bahia com 408 diagnósticos, e o menor sendo Piauí com 111 diagnósticos (BRASIL, 2017).

Ainda para Lago RF e Costa NR (2017), a resposta brasileira à epidemia de aids é reputada como bemsucedida, com seu caráter amplo, que envolveu prevenção, tratamento e respeito aos seres humanos enfatizando seus direitos. Mobilizando a sociedade civil e sendo vista como um elemento crucial para a conformação de respostas, influenciado assim decisivamente para o desenvolvimento de todas as esferas de ações para a diminuição da epidemia.

Tendo em vista os pontos levantados, é de grande importância ressaltar o valor dessa pesquisa. É de grande valia entender a sintomatologia e as alterações imunológicas vividas pelos portadores do HIV. Embora se tenha informações sobre o assunto, ainda existe uma população leiga e desfavorecida. $O$ que torna importante a contribuição desta pesquisa para o esclarecimento aos sintomas e tratamento da doença. Portanto, este trabalho tem como objetivo realizar um levantamento bibliográfico com abrangência entre os anos de 2010 a 2019, dos sintomas e alterações imunológicas decorrentes da infecção do HIV. Bem como, identificar quais as principais doenças relacionadas como sua sintomatologia.

\section{MÉTODOS}

Estudo de revisão integrativa da literatura, realizada uma busca, no período de agosto e setembro de 2019. As bases de dados: Biblioteca Virtual de Saúde (BVS) entre as bases de dados, Literatura Latino-americana e do Caribe em Ciências da Saúde (LILACS), Medical Literature Analysis and Retrieval System Online (MedLine) e Scientific Electronic Library Online (SciELO) que é uma base independente. Procurando responder à pergunta norteadora: quais os principais sintomas e alterações imunológicas decorrentes do HIV em seus portadores entre 2010 e 2019 ?

Para iniciar a busca nos bancos de dados usou-se os descritores que estão presentes na plataforma dos Descritores em ciências da Saúde (DECs), tendo em vista que para uma busca ampla da literatura foram necessárias algumas combinações. Os descritores usados foram: infecções por HIV e sinais e sintomas, HIV e Doenças do sistema imunitário. Para a combinação dos termos foi usando o operador booleano "AND".

Foram utilizados como critérios de inclusão: estudos primários disponíveis na integra nas bases de dados. Sendo selecionados aqueles cuja metodologia adotada permitisse obter evidências fortes: ensaios clínicos randomizados controlados individuais, estudos do tipo coorte, estudos com delineamento de pesquisa quase experimental e estudos transversais e longitudinais e estudos epidemiológicos e com assunto principal infecções por HIV. Os critérios de exclusão focaram-se nas produções duplicadas, estudos de revisão, teses, dissertações e editoriais.

Para construção da seleção dos artigos que estão descritos logo abaixo na (Figura 1) após os critérios de inclusão, em primeira instancia houve a seleção dos artigos nos bancos de dados através dos títulos dos estudos, após essa seleção houve uma leitura dos resumos dos artigos sendo excluídos aqueles que não tinham uma linha de estudo para a construção da seleção, logo em seguida houve uma leitura dos resumos sendo eliminados mais estudos que através dessa leitura foi visto que não iam contribuir para o estudo, e por fim após dessas leituras, para a seleção final houve uma leitura criteriosa de todos os artigos restantes, sendo selecionados os dez estudos que contribuíram para a formação desse estudo. 
Figura 1 - Fluxograma do processo de investigação, seleção e inclusão de artigos nas bases de dados, LILACS e MEDLINE. Teresina, PI, Brasil, 2019.

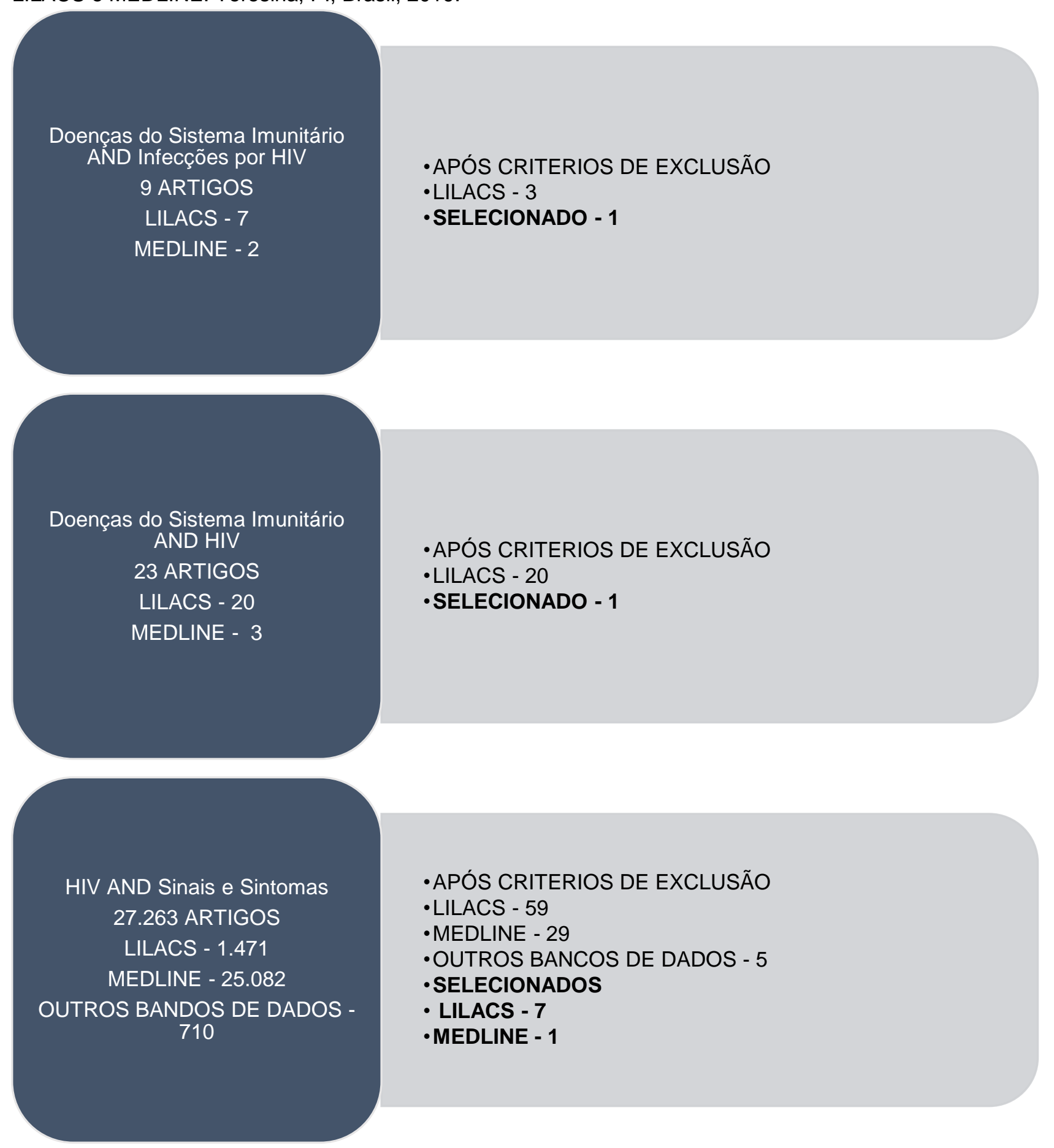

Fonte: Dias JO, et al., 2019. Baseado em Biblioteca Virtual de Saúde (BVS), 2019.

\section{RESULTADOS E DISCUSSÃO}

Foram selecionados dez estudos com dados coletados por meio de um questionário, elaborado pelo autor, contendo as seguintes variáveis: títulos; resultado; conclusão; periódico. Analisando os principais resultados e os periódicos de publicação, sendo identificado publicações voltadas para doenças sexualmente transmissíveis (DST), presente no Jornal Brasileiro de Doenças Sexualmente Transmissível, ainda foi possível observar uma publicação em uma revista voltada para assuntos da fonoaudiologia, mostrando alterações auditivas em indivíduos com HIV/AIDS, principalmente no Potencial Evocado Auditivo de Tronco Encefálico (PEATE), sendo que o grupo que fazia uso dos antirretrovirais apresentaram mais alterações. 


\section{Revista Eletrônica Acervo Saúde / Electronic Journal Collection Health ISSN 2178-2091}

Quadro 1 - Caracterização dos estudos quanto autor/ano; títulos; resultados; periódico. Teresina, Piauí, Brasil. 2019

Autor/Ano

Inagaki ADM, et al. (2009)

Soroprevalência de anticorpos para toxoplasmose, rubéola, citomegalovírus, sífilis e HIV em gestantes

sergipanas

Matas CG, et al. (2010)

Manifestações eletrofisiológicas em adultos com HIV/AIDS submetidos e não-submetidos à terapia anti-retroviral

Santos KF, et al. (2010)

Oliveira FL, et al. (2011)

Ferreira BE, Oliveira IM, Panlago AMN (2012) Alterações Nutricionais em pacientes com

Resultados

\section{Periódico}

A soropositividade para

toxoplasmose incrementou com a

idade. A prevalência de anticorpos

IgG para toxoplasmose.

Foram encontradas alterações em todos os PEA nos indivíduos com HIV/AIDS, principalmente no

PEATE; sendo que neste, o grupo exposto ao tratamento antirretrovira apresentou mais alterações.

As taxas de prevalência de coinfecção HIV/HCV variam em

diferentes partes do país e do mundo, devido a fatores epidemiológicos, vias de transmissão e fatores de risco.

Os melhores escores nas facetas dor, lazer, apoio social, ambiente físico e crenças pessoais foram os com maiores níveis de CD4 ( $\mathrm{p}<$

$$
\text { 0,05). }
$$

Dos 62 pacientes, 53,2\% eram do

sexo feminino, $53,2 \%$ estavam unidade de referência do município de Belém - Pará

eutróficos segundo o IMC e $56,7 \%$ faziam uso de algum inibidor de

protease. As mulheres

apresentaram mais a forma mista

da lipodistrofia e os homens, a
Revista da sociedade brasileira de medicina tropical

Pró-Fono Revista de atualização Científica

Revista Brasileira de Análises Clínicas

Revista Brasileira Epidemio

\author{
DST - Jornal Brasileiro de \\ Doenças Sexualmente \\ Transmissível
} lipoatrofia. 


\section{Revista Eletrônica Acervo Saúde / Electronic Journal Collection Health ｜ ISSN 2178-2091}

Silva VS, Mori RMSC

Guimarães SM (2012)

Manifestações clínicas e Sorológicas conflitantes de sífilis em coinfecção pelo HIV

Pereira RS, et al. (2014)

Fatores associados à infecção pelo HIV/AIDS entre adolescentes e adultos jovens matriculados em

Centro de Testagem e Aconselhamento no estado da Bahia, Brasil

Comparação de testes laboratoriais para o

Campos KR, et al. (2015)

Araldi LM, et al. (2016)

Ferreira DP, Souza FA, Motta MCS (2019) diagnóstico de infecção por vírus linfotrópicos de

células T humanas do tipo 1 (HTLV-1) e tipo (HTLV-

Pessoas idosas com o vírus da imunodeficiência

humana: infecção diagnóstico e convivência

Prevalência de coinfecção HIV/Tb em pacientes de hospital de referência na cidade do Rio de Janeiro
2) em pacientes infectados por HIV-1

Deve ser oferecido a todo paciente com sífilis o teste sorológico do HIV

e vice-versa, na tentativa de um

diagnóstico de coinfecção rápido.

Os dados da presente pesquisa mostraram maior frequência de soropositivos entre indivíduos do sexo feminino.

A coinfecção por HTLV foi confirmada, considerando o resultado positivo em qualquer um dos três ensaios confirmatórios.

Esses resultados são semelhantes aos encontrados em outros

estudos, os quais referem que a maioria das pessoas com 50 anos ou mais infectados por HIV é do sexo masculino.

O diagnóstico de TB nos coinfectados prevaleceu a forma clínica pulmonar (80\%). No teste do esfregaço, $(66,6 \%)$ apresentaram

resultado positivo, $(74,9 \%)$

radiologia sugestiva e $100 \%$ dos pacientes apresentaram resistência a rifampicina no teste do Gene Xpert.
Ciências e Saúde Coletiva

Rev Inst Adolfo Lutz

Rev Min Enferm

Revista online de pesquisa cuidado é fundamental

Fonte: Dias JO, et al., 2019. Baseado em Biblioteca Virtual de Saúde (BVS), 2019.

REAS/EJCH | Vol.Sup.n.40 | e2715 | DOI: https://doi.org/10.25248/reas.e2715.2020 Página 6 de 11 
Foi realizada uma análise e seleção criteriosa dos artigos incluindo-se os estudos que se associavam à questão norteadora. Posteriormente realizou-se a avaliação dos estudos quanto ao nível de evidência (NE) seguindo as normas da Oxford Centre Evidence Based Medicine (2009) (Quadro 2).

Relacionando os tipos de estudos inseridos, verificou-se que 2 (20\%) eram artigos de coorte transversal, $2(20 \%)$ ensaios clínicos, 2 (20\%) estudo observacional, 1 (10\%) relato de caso, 2 (20\%) estudo descritivo, 1 (10) estudo exploratório, descritivo de abordagem qualitativa (Quadro 2).

Quadro 2 - Classificação dos estudos, autor, área de conhecimento, tipo de estudo e nível de evidência (NE)

\begin{tabular}{|c|c|c|}
\hline $\begin{array}{l}\text { Autores/ } \\
\text { Ano }\end{array}$ & Tipo de estudo & $\begin{array}{l}\text { Nível de } \\
\text { Evidencia }\end{array}$ \\
\hline Inagaki ADM, et al. (2009) & $\begin{array}{l}\text { Estudo populacional, epidemiológico, de } \\
\text { coorte transversal }\end{array}$ & 2B \\
\hline Matas CG, et al. (2010) & Ensaios clínico & 1B \\
\hline Santos KF, et al. (2010) & Estudo observacional & $2 \mathrm{C}$ \\
\hline Oliveira FL, et al. (2011) & Relato de caso & 4 \\
\hline $\begin{array}{l}\text { Ferreira BE, Oliveira IM, Panlago AMN } \\
\qquad(2012)\end{array}$ & Coorte transversal & $2 \mathrm{~B}$ \\
\hline $\begin{array}{l}\text { Silva VS, Mori RMSC, Guimarães SM } \\
\qquad(2012)\end{array}$ & Descritivo analítico de coorte transversal & 2B \\
\hline Pereira RS, et al. (2014) & $\begin{array}{c}\text { Estudo observacional, com delineamento } \\
\text { transversal }\end{array}$ & $2 \mathrm{C}$ \\
\hline Campos KR, et al. (2015) & Ensaios clínico & 1B \\
\hline Araldi LM, et al. (2016) & $\begin{array}{l}\text { Estudo exploratório, descritivo de abordagem } \\
\text { qualitativa }\end{array}$ & $2 \mathrm{~B}$ \\
\hline Ferreira DP, Souza FA, Motta MCS (2019) & Estudo descritivo, retrospectivo e seccional & 2B \\
\hline
\end{tabular}

Fonte: Oxford Centre Evidence Based Medicine, 2009.

Após o levantamento dos estudos, houve uma leitura buscando levantar evidencias que determinaram a importância dos estudos. Havendo comparações entre os autores, buscando pontos com mais relevância. Determinando entre os estudos comparações entre os achados da literatura.

Os estudos selecionados mostraram grandes evidencias para a construção da pesquisa, entre as publicações analisadas, tiveram presentes diversos tipos de estudos que apresentam grande relevância. Os estudos populacionais, estudos de coortes, estudos descritivos e os ensaios clínicos, apresentaram como principal conteúdo a prevalência de soropositivos entre os diferentes públicos, assim como as principais coinfeções que são vividas por esses pacientes. Ainda foi possível observar o grau de efeitos colaterais que os retrovirais causam em seus usuários, fazendo com que o preconceito e o medo da exposição se faça presente em seu dia a dia.

A seleção buscou determinar o que cada estudo concluiu ao final das pesquisas, como mostra no Quadro 3, foi possível observar na maioria dos estudos, que os efeitos adversos devido a co-infecções são os principais causadores de sintoma frente ao HIV. Santos KF, et al (2010), evidencia que entre os pacientes coinfectados HIV/HCV, as infecções oportunistas representam a maior falha terapêutica, que pode ser devida ao desenvolvimento da resistência a alguma droga antirretroviral ou ao uso inadequado da terapia. 
Quadro 3 - Classificação dos estudos, autor(a), título, conclusão. Teresina, Piauí, Brasil. 2019.

\begin{tabular}{cc}
\hline $\begin{array}{c}\text { Autores/ } \\
\text { Ano }\end{array}$ & Titulo \\
\hline $\begin{array}{c}\text { Inagaki ADM, } \\
\text { et al. (2009) }\end{array}$ & $\begin{array}{c}\text { Soroprevalência de anticorpos para } \\
\text { toxoplasmose, rubéola, citomegalovírus, } \\
\text { sífilis e HIV em gestantes sergipanas }\end{array}$
\end{tabular}

Matas CG, et al. (2010)

Santos KF, et al. (2010)

Oliveira FL, et al. (2011)

Ferreira BE, Oliveira IM, Panlago AMN (2012)

Silva VS, Mori RMSC, Guimarães SM (2012)

Pereira RS, et al. (2014)

Campos KR, et al. (2015)

Araldi LM, et al. (2016)

Ferreira DP, Souza FA, Motta MCS (2019)
Manifestações eletrofisiológicas em adultos com HIV/AIDS submetidos e não-submetidos à terapia anti-retroviral

Alterações laboratoriais encontradas em indivíduos co-infectados pelo Vírus da Imunodeficiência Humana (HIV) e pelo vírus de Hepatite $\mathrm{C}(\mathrm{HCV})$

\section{Manifestações clínicas e Sorológicas} conflitantes de sífilis em coinfecção pelo HIV

Qualidade de vida de portadores de HIV/AIDS e sua relação com linfócitos CD4+, carga viral e tempo de diagnóstico.

Alterações Nutricionais em pacientes com Lipodistrofia associada ao HIV/AIDS em uma unidade de referência do município de Belém -

$$
\text { Pará }
$$

Fatores associados à infecção pelo HIV/AIDS entre adolescentes e adultos jovens matriculados em Centro de Testagem e Aconselhamento no estado da Bahia, Brasil

Comparação de testes laboratoriais para o diagnóstico de infecção por vírus linfotrópicos de células $T$ humandas do tipo 1 (HTLV-1) e tipo (HTLV-2) em pacientes infectados por HIV-1

Pessoas idosas com o vírus da imunodeficiência humana: infecção diagnóstico e convivência

Prevalência de coinfecção HIV/Tb em pacientes de hospital de referência na cidade do Rio de Janeiro

\section{Conclusão}

Devido à possibilidade de profilaxia e tratamento gestacional, com indiscutível benefício para mãe, feto e recém-nascido, sob risco de aquisição de infecção causada pelo HIV e Treponema pallidum e à chance de prevenção de infecção gestacional a partir do conhecimento da soronegatividade para toxoplasmose

Indivíduos com HIV/AIDS podem apresentar alterações no sistema nervoso auditivo periférico e central, sendo que o grupo exposto a tratamento anti-retroviral apresenta mais alterações na via auditiva em tronco encefálico.

Entre os pacientes co-infectados HIV/Hepatite C $\mathrm{HCV}$, a ocorrência de uma infecção oportunista representa, na maioria das vezes, uma falha na terapêutica, que pode ser devida ao desenvolvimento da resistência a alguma droga antirretroviral ou ao uso inadequado da terapia.

Reforça-se a importância da realização de novas sorologias não treponêmicas quando diante de clínica altamente sugestiva de sífilis, e da adoção de um tratamento precoce a fim de evitar complicações da doença.

Com os dados deste estudo é possível perceber que análises isoladas de variáveis na tentativa de identificar aquelas que afetam a qualidade de vida

(QV) do paciente portador do HIV são pobres

As alterações antropométricas e bioquímicas foram frequentes nos pacientes estudados, o que torna o acompanhamento nutricional individualizado uma importante ferramenta no tratamento de pacientes que apresentam a lipodistrofia associada ao HIV

Considera-se fundamental a sensibilização para uma mudança de atitude entre adolescentes e adultos jovens frente à epidemia da AIDS, incentivando o comportamento de autoproteção, cujo impacto contribui para a situação de saúde e mudança do perfil da infecção e doença nesse grupo populacional.

Observou-se que, em pacientes infectados pelo HIV-1, o algoritmo adotado deve considerar a zona cinza na triagem sorológica; principalmente quando se utiliza apenas um kit EIA.

Pode-se concluir que as pessoas idosas possuíam conhecimento restrito em relação ao HIV antes de descobrirem que eram soropositivas, demonstrando a importância da realização de ações educativas com vistas à prevenção.

As drogas que apresentaram-se mais resistentes neste grupo foram rifampicina, isoniazida $e$ estreptomicina $(87,5 \%)$.

Fonte: Dias JO, et al., 2019. Baseado em Biblioteca Virtual de Saúde (BVS), 2019. 
Em relação aos pacientes que apresentam melhor condição em seu sistema imunológico, apresentam uma contagem de celular $\geq 500 \mathrm{~mm}^{3} \mathrm{com}$ um melhor escore na contagem de células CD4+ abaixo de 500 . Sendo observado dentro dos escores em pacientes com níveis mais altos de células CD4+.

O nível de independência tem o uso dos medicamentos como um grande potencial negativamente, sendo assim o diagnóstico precoce proporciona fatores que permitem melhorar a imunologia e esquemas terapêuticos com um menor número de medicamentos, influenciando positivamente na qualidade de vida dos pacientes (FERREIRA BE, OLIVEIRA IM e PANIAGO AMM, 2017).

O HIV, é visto como um dos principais vilões das doenças que afetam o sistema imunológico a décadas, esse vírus é silencioso, sua transmissão é feita através de atos sexuais sem preservativos, como pelo contado com fluidos sanguíneos entre o portador e o não portador. O vírus pode viver anos no ser humano e não ser identificado, um dos principais meios de avaliar o sistema imunológico do portador do vírus, é através da contagem de células T CD4+, foi visto nos estudos que um bom escore dessas células é $\geq 500 \mathrm{~mm}^{3}$.

No estudo de Santos KF, et al. (2010), corrobora com o acima, evidenciando alterações laboratoriais em indivíduos co-infectados pelo HIV e pelo vírus da Hepatite C, determinou uma contagem de células T CD4+, houve uma separação da quantidade de carga viral do HIV entre pacientes que fizeram uso dos antirretrovirais e os que não usaram o método, apresentando uma grande diferença nos valores das células, o grupo que fez uso dos antirretroviral apresentou na contagem $(p=0,008)$, os que não utilizaram a medicação obtiveram $(p=0,867)$, determinando assim que o grupo que fez uso dos antirretrovirais apresentaram uma quantidade menor de células T CD4+.

$\mathrm{O}$ uso dos antirretrovirais podem trazer mudanças significativas na rotina das pacientes co-infectados pelo HIV, o uso contínuo dessa terapia medicamentosa causa reações adversas de grande importância clínica sendo as mais corriqueiras: o emagrecimento, alterações lipídicas, perda de gordura corporal e osteopenia. Entretanto é notável que apenas a condição de ser portar o vírus sem que se faça o uso das medicações imunossupressoras não ocasiona estes sinais clínicos. Foi possível observar nos estudos, mesmo com uma diferença de sete anos de publicação, que ambos determinaram a mesma evidencia, mostrando que os portadores do vírus HIV, deve apresentar em seu organismo um número maior de celular T CD4+, isso se o paciente não fizer uso dos antirretrovirais.

Segundo Campos KR, et al. (2015), realizou um estudo com mais de 1500 pacientes com o objetivo de ampliar e confirmar a performasse dos testes sorológicos de triagem, concluindo que os pacientes infectados por HIV-1, o algoritmo adotado deve-se considerar dentro de uma zona cinza na triagem sorológica. Confirmando ainda que na junção do HIV-1/Vírus T-Linfotrópico Humano do Tipo 1 (HTLV-1) pode ocorrer uma progressão rápida para AIDS pelo fato do HTLV-1 imortalizar a célula e elevar o número de células $T$ CD4+, aumentando assim a replicação viral de reservatórios latentes.

No estudo realizado por Aradi LM, et al. (2016), com pessoas idosas com HIV, demostra o quanto é demorado o diagnóstico, em relação a essa população, podendo levar meses ou até anos para que seja comprovado o diagnóstico. Pois os profissionais de saúde acreditam que a AIDS é uma doença que vive longe da população idosa, e não relacionada a mesma com a possibilidade de contaminação. Evidenciando assim nesse estudo o número de profissionais que não possuem como rotina a requisição do teste anti-HIV para pessoas idosas, pois relacionam os sintomas a doenças relacionadas a idade, tornando assim a identificação da infecção demorada. Pontando, nesse estudo foi evidenciando que o HIV é uma infecção silenciosa, não apresenta sintomas evidentes, dificultando assim o diagnóstico.

Portanto o HIV estar presente em todas as populações desde os jovens aos idosos, e sua maneira silenciosa de viver no organismo, pode proporcionar um diagnóstico tardio principalmente na população idosa, pelo fato de se acreditar que esse grupo é menos propicio a contrair o vírus, o estudo determinou que existe uma grande população na terceira idade com o HIV. Sendo que, o diagnóstico em sua maioria é determinado após se contrair alguma doença oportunista, proporcionando a esse paciente a busca quase que obrigatória de cuidados. As doenças oportunas e/ou co-infecções são os grandes vilões dos portadores do vírus HIV, é através delas que o vírus se mostra presente. A hepatite $C$, sífilis, Tuberculose são as mais presentes nesses pacientes, causando alterações sintomáticas associadas a doença, dificultando assim a identificação de sinais e sintomas relacionados ao HIV e muitas vezes sendo subnotificada nos serviços de saúde. 
No estudo de Ferreira DP, Souza FA e Motta MCS (2019), mostrou a prevalência de coinfecção HIV/Tb em pacientes de um hospital do Rio de Janeiro, determinou que a Tuberculose é uma das principais causas de morte por doença infecciosa no mundo, em relação a Aids é a quarta causa de morte por doenças infecciosas e a primeira por pacientes com Aids. O diferencial dela frente aos sintomas clínicos no HIV é sua ocorrência mais frequente fora dos pulmões e de maneira disseminada no corpo. No Brasil a taxa de novos casos de Tuberculose representa 15\% e estão entre pessoas infectadas pelo vírus da imunodeficiência, o que determina o reforço para recomendar e rastrear sistematicamente a Tuberculose (TB) em pacientes hospitalizados com doenças relacionadas ao HIV.

Os pacientes infectados pelo HIV possuem imunossupressão avançada que representam com mais frequência a doença na forma de disseminação hematogênica com envolvimento multiorgânico (FERREIRA DP, et al., 2019). Portanto, a TB é observada como uma das doenças oportunistas que mais afetam os pacientes portadores de HIV, e através dela que os sintomas não observados. Entres esses sintomas é visto o emagrecimento.

As anormalidades lipídicas são mais evidentes dentro dos infectados pelo HIV logo após a introdução dos antirretrovirais, tendo a hipercolesterolemia e a hipertrigliceridemia os distúrbios mais marcantes. Partindo para essa observação o presente autor determinou que algumas alterações nos parâmetros bioquímicos, são mais presentes no sexo feminino e outros no masculino, porém, somente a hipertrigliceridemia estar estatisticamente associada à população masculina (SILVA VS, et al., 2012). Ainda no estudo de Silva VS, Mori RMSC e Guimarães SM (2012), os pacientes apresentavam alterações corporais condizentes com a lipodistrofia, e alguns mostravam diferenças de níveis lipídicos alterados. Dentro dessas alterações metabólicas estão o aumento da resistência periférica à insulina, diabetes mellitus, e alterações dos lipídios, na distribuição da gordura corpórea, acidose lática, osteopenia, podem ser observadas em indivíduos infectados pelo HIV, quem tem uma relação ao uso dos antirretrovirais.

As alterações nutricionais são frequentes nos pacientes com HIV, apresentando os déficits de adequação da prega cutânea tricipital, da circunferência do braço e da braquial, além ainda de ter um grande risco de aumentar as alterações metabólicas, e a presença de dislipidemia, as alterações mais observadas e evidentes estão divididas entre os sexos masculinos e femininos. Determinando assim que essas mudanças podem ocorre em diferentes gêneros (SILVA VS, et al., 2012). A desnutrição é um sintoma evidente em alguns pacientes, devido a rejeição que pode ocorrer do organismo frente aos antirretrovirais no início do tratamento.

Os pacientes que apresentam co-infecção relacionada a HIV/Hepatite $\mathrm{C}$ que apresentam as infecções oportunistas, vivem na maioria das vezes uma falha terapêutica, que pode ser determinado pela resistência a alguma droga antirretroviral ou ao uso inadequado.Pode identificar que o paciente possui a doença avançada ou pode ser devido a uma reconstituição imunológica após início da terapia, pois a melhora imunológica vai resultar em resposta inflamatória a infecções oportunistas pré-existentes, que eram desconhecidas, evidenciando assim a importância de avaliação laboratorial dos dados analisados (SANTOS KF, et al., 2010).

No estudo de Matas CG, et al. (2010), foi possível perceber que os portadores com HIV/AIDS, independentemente da exposição ao tratamento antirretroviral, podem perceber alterações na via auditiva central, comprometendo o caráter lesional (efeito eletrodo), ou funcional (efeito orelha), que podem não ser identificados na avaliação audiológica convencional. Este estudo relaciona o uso da terapia antirretroviral a afeitos adversos no sistema auditivo relacionado comumente com diminuição da audição.

Sendo assim, os estudos mostraram que os pacientes com HIV, vivem um tempo sem serem cientes da doença pelo fato da mesma ser silenciosa. O paciente só passa a ser conhecedor da infecção após a realização de testes específicos, ou através da manifestação de qualquer doença oportuna que pode trazer inúmeras alterações no seu cotidiano, considerando isto faz-se necessário que os indivíduos que apresentem quaisquer alterações sugestivas para infecção pelo vírus procurem os centros de saúde especializados com intuito de realização dos testes para detecção precoce e início da terapia antirretroviral.

\section{CONSIDERAÇÕES FINAIS}

Após o levantamento bibliográfico que construiu este estudo surgiram considerações a respeito das manifestações clínicas do vírus HIV no organismo humano, que na grande maioria das vezes apresenta se 
assintomática, sendo muito frequente o diagnóstico a partir das doenças oportunistas como a tuberculose que altera a imunidade dos portadores do vírus. Constatou-se ainda que inexistem poucas evidencias direcionadas ao vírus do HIV de forma isolada, em sua maioria dos estudos procuram relacionar a infecção com outras patologias, que apresentam sintomatologia características da co-infecção. Sendo assim, o estudo evidencia a fundamental importância de buscar estudos robustos que proporcione um conhecimento direcionado para os sinais e sintomas decorrente da patologia.

\section{REFERÊNCIAS}

1. ARALDI LM, et al. Pessoas idosas com o vírus da imunodeficiência humana: infecção diagnóstico e convivência. Rev Min Enferm. v. 20, n. e948, 2016.

2. CAMPOS KR, et al. Comparação de testes laboratoriais para o diagnóstico de infecção por vírus linfotrópicos de céculas T humanas do tipo 1 (HTLV-1) e tipo (HTLV-2) em pacientes infectados por HIV-1. Rev Inst Adolfo Luiz. v. 74, n. 1, p. 57-65, 2015.

3. DATASUS - Disponível em <http://www2.aids.gov.br/cgi/tabcgi.exe?tabnet/br.def>. Acesso em 20 de abril de 2017 às 14:00 horas.

4. FERNANDES NM, et al. Vulnerabilidade à infecção do HIV entre casais sorodiscordantes no Rio de Janeiro, Brasil. Cad. Saúde Pública. v. 33, n 4, 2017.

5. FERREIRA BE, et al. Qualidade de vida de portadores de HIV/AIDS e sua relação com linfócitos CD4+, carga viral e tempo de diagnóstico. Rev Bras Epidemiol. v. 15, n. 1, p. 75-84, 2012.

6. FERREIRA DP, et al. Pevalência da coinfecção HIV/Tb em pacientes de um Hospital de referência na cidade do Rio de Janeiro. Revista online de pesquisa cuidado é fundamental. v. 11, n. Esp, p. 358-362, 2019.

7. INAGAKI ADM, et al. Soroprevalência de anticorpos para toxoplasmose, rubéola, citomegalovírus, sífilis e HIV em gestantes sergipanas. Revista da Sociedade Brasileira de Medicina Tropical. v. 42, n. 5, p. 532-536, set-out, 2009.

8. LAGO RF, COSTA NR. Comunidades de especialistas e formação de interesses no programa de aids no Brasil. Ciência \& Saúde Coletiva. v. 22, n. 5, p. 1479-1488, 2017.

9. MATAS CG. Manifestações eletrofisiológicas em adultos com HIV/AIDS submetidos e não-submetidos à terapia antiretroviral. Pró-Fono Revista de Atualização Ciêntifica. v. 22, n. 2, p. 107-112, abr- jun, 2010.

10. MELO BP, et al. Respostas agudas do exercício físico em pessoas infectadas pelo HIV: uma revisão sistemática. Rev Bras Med Esporte, v. 23, n. 2, Mar/Abr, 2017.

11. MENDES KDS, et al. Revisão integrativa: método de pesquisa para a incorporação de evidências na saúde e na enfermagem. Texto \& Contexto Enfermagem, Florianópolis, v. 17, n. 4, p. 758-64, 2008.

12. OLIVEIRA FL, et al. Manifestações clínicas e sorológicas conflitantes de sífilis em coninfecção pelo HIV. J bras Doenças Sex Transm. v. 23, n. 4, p. 222-224, 2011.

13. PEREIRA BS, et al. Fatores associados à infecção pelo HIV/AIDS entre adolescentes e adultos jovens matriculados em centro de testagem e aconselhamento no Estado da Bahia, Brasil. Ciência e Saúde Coletiva. v. 19, n. 3, p. 747758, 2014.

14. RACHID M, SCHECHTER A. Manual de HIV/AIDS. 10 ed - Rio de Janeiro - RJ: Thieme Revinter Publicações Ltda. 2017. 276p.

15. SANTOS KF, et al. Alterações laboratoriais encontradas em indivíduos co-infectados pelo Vírus da Imunodeficiência Humana (HIV) e pelo Vírus da Hapatite C (HCV). Revista Brasileira de Análises Clínicas. v. 42, n. 1, p. 21-24, 2010.

16. SILVA VS, et al. Alterações nutricionais em pacientes com lipodistrofia associada ao HIV/AIDS de uma unidade de referência do município de Belém - Pará. Jornal Brasileiro de doenças sexualmente transmissíveis. v. 24, n. 4, p. 233-238, 2012. 